\title{
Aortic stiffness and flow-mediated dilatation in normotensive offspring of parents with hypertension - CORRIGENDUM
}

\author{
Harun Evrengul, Halil Tanriverdi, Ismail D. Kilic, Dursun Dursunoglu, Emin E. Ozcan, Asuman Kaftan,
} Mustafa Kilic

First published online: 17 April 2012

doi:10.1017/S104795111200008X, Published by Cambridge University Press, 21 February 2012.

The authors apologise for the following errors within the Abstract on page 1, and within the text on page 5 of the article.

\section{Page 1, Abstract:}

The first sentence of the Methods section should read:

Methods: A total of 140 healthy, non-obese subjects in the age group of 18-22 years were included in this study and divided into two groups.

The first sentence of the Conclusion section should read: Conclusion: We observed blunted endotheliumdependent dilatation and aortic stiffness in offspring of hypertensive parents compared with offspring of normotensive parents.

Page 5:

In the first column, seven lines down, the sentence should read:

In the study of Yasmin et al, systolic, diastolic, mean arterial pressures, as well as homocysteine, creatinine, and glucose levels, were higher in offspring of hypertensive parents compared with offspring of normotensive parents, whereas in our study, groups were very homogeneous and these parameters were similar between groups.
In the first column, 18 lines down, the sentence should read:

Kucerova et $\mathrm{al}^{25}$ in a recent study reported that large-artery properties are altered in offspring of hypertensive parents compared with offspring of normotensive parents, but their findings from that cross-sectional study suggest that the alterations in arterial function in offspring of hypertensive parents are determined mainly by an increased blood pressure and age-related haemodynamic changes.

The last paragraph should read:

To conclude with, we observed blunted endotheliumdependent dilatation and aortic stiffness in offspring of hypertensive parents compared with offspring of normotensive parents. This is evident in the absence of overt hypertension and other diseases, suggesting that parental history of hypertension is a risk for subclinical atherosclerosis and it may contribute to the progression to hypertension and overt atherosclerosis in later life.

\section{Reference}

Evrengul H, Tanriverdi H, Kilic ID, Dursunoglu D, Ozcan EE, Kaftan A, Kilic M. Aortic stiffness and flow-mediated dilatation in normotensive offspring of parents with hypertension. Published by Cambridge University Press, 21 February 2012. 